\title{
The impact of introduced predators on an island endemic, the St Helena Plover, Charadrius sanctaehelenae
}

\author{
FIONA BURNS, NEIL MCCULLOCH, TAMÁS SZÉKELY and MARK BOLTON
}

\begin{abstract}
Summary
We investigated the impact of introduced predators on the productivity of the St Helena Plover Charadrius sanctaehelenae, a shorebird endemic to the South Atlantic island of St Helena. The nest predator species identified have all been introduced to St Helena in the last 510 years, and all are species that are known to be invasive on other islands. The species responsible for taking the largest proportion of eggs was the domestic cat Felis catus, with rats (Rattus rattus or R. norvegicus) and Common Myna Acridotheres tristis taking smaller proportions. Nest survival varied spatially and was correlated with an index of cat density. No relationship was observed between the number of nesting attempts per pair in a year and predator density. The resulting estimates of productivity were insufficient in some areas to allow stable populations to persist locally. Future work should focus on assessing the population level impacts of current and reduced predator densities to St Helena Plovers, and understanding the influence of resource availability and habitat structure on the densities and impacts of predators.
\end{abstract}

\section{Introduction}

In general, predation rates represent a balance between the evolutionary adaptations of predator and prey (Ricklefs 1969). The absence of a shared history can therefore leave prey species poorly adapted to cope with predators. This is often the case for prey species endemic to isolated oceanic islands, whose native faunas are disharmonic and commonly lack certain groups, notably predatory mammals (Gillespie and Clague 2009). This study assesses the impact of a number of introduced predators on an endangered bird species, the St Helena Plover Charadrius sanctaehelenae.

The St Helena Plover or Wirebird ("Critically Endangered"; McCulloch 2009, BirdLife International 2009) is endemic to the island of St Helena in the South Atlantic Ocean. All the endemic bird species of St Helena present at the island's discovery by humans in 1502 have since become extinct, except the plover (Olson 1975). St Helena had no native mammals and these extinctions were surely influenced by the predatory mammal species introduced to the island after its discovery, including cats Felis catus, dogs Canis familiaris, rats Rattus rattus and R. norvegicus and mice Mus musculus (Ashmole and Ashmole 200o). The Common Myna Acridotheres tristis (Rowlands et al. 1998) was also introduced and is a potential predator of eggs and small chicks.

Given the severe impacts of introduced predators elsewhere, we might expect the plovers to be similarly influenced, and high levels of predation are a possible reason for the current small population size. However, the plovers have persisted in the presence of introduced predators for hundreds of years and so the effects of predation remain unclear. Indeed, several aspects of 
the species' life history indicate that the St Helena Plover may exhibit greater resilience to introduced predators than other insular endemics. The annual survival rate of adult St Helena Plovers is high (Burns et al. 2013) and therefore predation is likely to primarily influence productivity. The plovers breed throughout the year, however (McCulloch and Norris 2001), and therefore may re-nest many times following both breeding failure and success. Other tropical species have been shown to be able to compensate for high nest predation in this way (Roper 2005).

With the aim of understanding the influence of introduced predators on the St Helena Plover more fully, our study had three objectives. First, what is the nest failure rate, what proportion of nest failures can be attributed to nest predation and what species are involved? Second, do indices of density of any predator species co-vary with nest survival? Third, do pairs at sites with low nest survival compensate by increasing the frequency of breeding attempts?

\section{Methods}

\section{Nest survival and re-nesting}

Data were collected between November 2007 and February 2010 on the island of St Helena $\left(15^{\circ} 58^{\prime} \mathrm{S}, 5^{\circ} 43^{\prime} \mathrm{W}\right)$. The exact periods over which data were collected are given below for each analysis). Data were collected at four study sites on St Helena: Deadwood Plain, Broad Bottom, Man and Horse, Prosperous Bay. The latter site encompasses Upper Prosperous Bay and Prosperous Bay Plain from previous publications. These sites collectively hold around half the global St Helena Plover population (total population size, $\bar{x}(2008-2012)=369 \pm 33.9$ SD (Saint Helena National Trust unpubl. data). The first three sites are grazed pastureland and the latter is semi-desert.

Nest survival data were collected throughout the core breeding season from November to February in both 2007 and 2008. Nests were visited every five days until a few days before the predicted hatch date, thereafter nests were checked at least every second day. Nest age was estimated using a calibration of egg density to egg age, previously calculated for this species (Furness and Furness 1981, Burns unpubl. data). Nests were checked from a distance where possible. Nests were classified as successful if chicks of an appropriate age were seen close to the nest scrape. The nest was deemed to have failed if the scrape was empty and parent birds were in the area but not exhibiting behaviour typical of adults with young chicks, or if the parent birds were not seen within $\sim 100 \mathrm{~m}$ of the nest. Chicks are unlikely to move far within 24 hours of hatching. Nesting failures were classified as follows: when eggs were absent they were classified as predated; eggs were assumed infertile if they failed to hatch when incubated to term, and abandoned if left unattended for over 24 hours. Nests that were abandoned after partial predation were counted as predated. A sample of pairs at each site $(n=6-10)$ were followed for a 12 month period, from April 2008 to March 2009, in order to assess annual productivity and re-nesting rates. At least one bird in these pairs was colour ringed; for full details of the colour ringing protocol see Burns et al. (2010).

\section{Nest predators}

Coincidental to monitoring nest survival, small $(2.5 \mathrm{~cm}$ diameter $)$ infra-red motion-sensitive nest cameras were set up at a sample of nests to identify nest predators following the design of Bolton et al. (2007). One additional nest was monitored by a camera in February 2010. The cameras were mounted on stakes $\sim 50 \mathrm{~cm}$ from the nest at a height of $\sim 25 \mathrm{~cm}$. All other components of the camera system were buried, to minimise conspicuousness. Nests with cameras were only disturbed to change the batteries; approximately every five days. The number of nests that were monitored with cameras was balanced between sites.

An index of cat density was estimated by calculating the deposition rate of scats along a 5-km transect at each site, using a similar approach to Harper (2004). Transects were conducted 
four times at each site, approximately monthly between June and October 2009. The location of all cat scats within $2 \mathrm{~m}$ of the centre line was recorded, and scats were collected for analysis. An index of Common Myna density was estimated using a similar transect approach between October 2007 and February 2008. A count was made of all mynas seen along a transect of approximately $1 \mathrm{~km}$ through each site, regardless of the distance from the transect line and including flying birds. No other fieldwork activities were undertaken during the transects, and therefore walking speed was assumed constant. The time taken to compete the transect was recorded, and the density of birds expressed as mynas second ${ }^{-1}$. This procedure was repeated on each visit to the site and sample sizes are given in Figure 3.

Two methods of estimating an index of rat abundance were used, as no single method is supported above others and results would be more robust if a similar pattern of activity was observed using multiple methods (Thomas 1999). We used flavoured wax blocks and oil impregnated chew sticks. These are designed to detect bite marks, which can be differentiated from those of other species due to differences in dentition. The blocks and chew sticks were distributed as transects of ten stations at $50 \mathrm{~m}$ intervals, six transects at each of the three pasture sites and eight transects in the semi-desert. The number and location of transects followed advice in Gillies and Williams (2002). Stations were deployed for four days. Transects were replicated twice at each site between June and October 2009. Both methods measured the proportion of objects chewed by rats out of the total deployed, excluding any blocks or sticks found to be missing or damaged.

For logistical reasons the indices of cat and rodent density were collected out of the main breeding season of the St Helena Plover. Whilst not ideal, we believe it is justifiable to compare nest survival with these predator indices. We would expect seasonal variation in cat densities to be driven both by the presence of a discrete breeding season and by pronounced climatic seasons, giving rise to variation in survival both directly and through availability of prey. These conditions hold true for studies which have found seasonal variation in cat densities (van Aarde 1979, Jones and Coman 1982). St Helena does not have pronounced seasons and the plovers nest and hold territory all year round. It is likely that cats also have a prolonged breeding season, as breeding is triggered by photoperiod (van Aarde and Skinner 1981) and on St Helena day length varies by less than two hours between summer and winter solstices. Furthermore, a seasonal difference in cat densities does not preclude the comparison of data collected in different seasons. The comparison would be invalidated only if the relationship between cat density and season varied between study sites.

\section{Analysis}

All statistical analyses were carried out in programme R (R Core Development Team 2004) unless otherwise stated. Nest survival was modelled using programme MARK (White and Burnham 1999). All explanatory variables were available for each nest. Explanatory variables assessed during model selection were: site; presence of a nest camera, year (factors); index of cat density, age of nest, laying date (covariates). Laying date represents the number of days between the start of the core field season, 5 November and the start of laying. The mean number of scats observed per transect was used as an index of cat density. Differences in the spatial and temporal scale of cat and nest monitoring permitted site-level analysis of nest survival in relation to cat density, but not nest-level analysis. Rat and myna densities were not included as explanatory variables; see results for justification. We used backward model selection based on minimising AIC. Two full models were used and simplified independently. One full model contained the variable site and the other the index of cat density; both models contained all other explanatory variables. During each round of model simplification, the variable that would lead to the greatest reduction in AIC upon deletion was removed. Model simplification stopped when deletion of additional variables would no longer reduce the AIC. Here, we only considered additive effects of the explanatory variables. 


\section{Results}

\section{Nest predators}

Sixteen of 20 recorded nest predation events occurred at night, between $20 \mathrm{Oh}_{30}$ and 04 hoo, and $65 \%$ of nests were predated by cats $(n=13$ nests; Figure 1$)$, probably including both domestic and feral cats. Camera footage also showed rats $(n=3)$ and mynas $(n=2)$, taking a smaller proportion of nests. At one nest, an egg at the point of hatching was overcome by ants. From nest visits, the chick was known to be alive when the ants entered the egg. However, it is not known whether the chick would have hatched in the absence of ants. The ant species was identified as the big-headed ant Pheidole megacephala which has been introduced to St Helena and is also the most common ant species on the island (Wetterer et al. 2007). Cattle or sheep are present on the majority of pasture sites in the St Helena Plover's range. Although livestock occasionally nudged the cameras out of alignment, they did not damage them. During one recording, a sheep was filmed taking at least one egg.

Cat density varied significantly between sites $\left(F_{3,12}=21.35, P=<0.001\right.$, adj. $R^{2}=0.803$; Figure 2a). Man and Horse and Prosperous Bay had significantly higher estimates than Broad Bottom (treatment contrasts, $t=7.151, P=<0.001 ; t=3.065, P=0.001$ respectively) but Deadwood Plain did not $(t=0.511, P=0.619)$. The most parsimonious model of myna density contained two levels of site representing the two habitats present, semi-desert and pasture. Pasture areas had higher densities of mynas than the desert $\left(F_{1,47}=42.82 \mathrm{P}=<0.001\right.$, arcsin transformed; Figure $\left.2 \mathrm{~b}\right)$. There was good congruence between the indices used to estimate rat density at three of the sites, but nearly complete disagreement at Prosperous Bay, the semi-desert area. Data from pasture sites showed no interaction between site and survey method. The index estimated using wax blocks was higher than that found using chew sticks, and there was some indication that rat densities were lower on one site, Deadwood Plain (Table 1 ). Since myna numbers varied only between habitats and we could not be confident of the estimate of rat density in the semi-desert these indices were not used in the analysis of nest survival.

\section{Nest survival and re-nesting}

The total number of plover nests followed over the two years was 173, and of these 65 hatched at least one egg. Overall daily nest survival (in the absence of explanatory variables) was

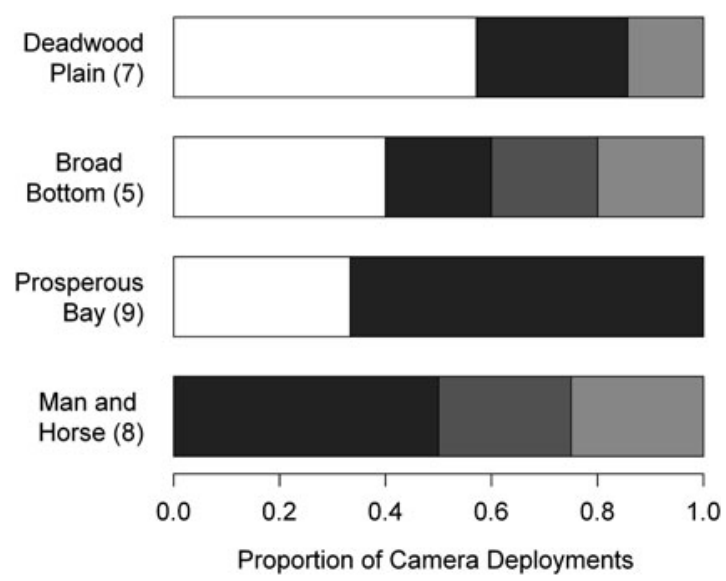

Figure 1. Summary of outcome of nests monitored by cameras at four study sites (sample size is indicated after each site name). Key: not predated (hatched or abandoned - white), eggs eaten by cats (black), eggs eaten by rats (dark grey), eggs eaten by another species (light grey). 


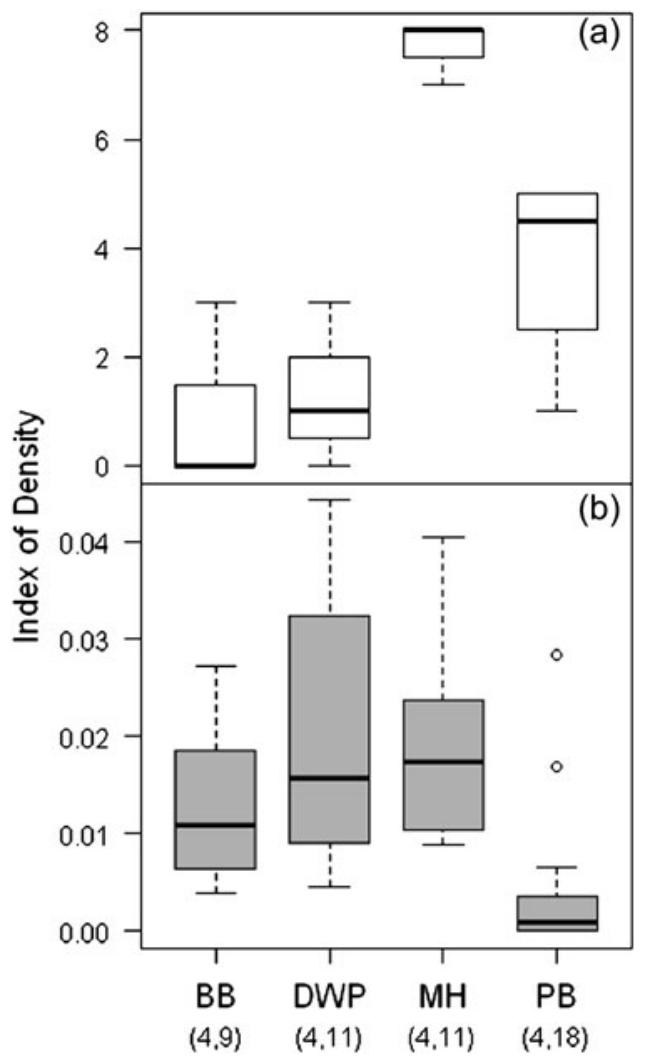

Figure 2. Indices of nest predator densities at four study sites, (a) Number of cat scats transect-1, (b) number of mynas seen second ${ }^{-1}$ transect $^{-1}$. Sample size (cat transect, myna transect) is shown in brackets below each site. Key: BB - Broad Bottom, DWP - Deadwood Plain, MH - Man and Horse, PB - Prosperous Bay.

0.950 (CI: 0.941-0.959), and survival to hatching 0.215 (CI: 0.156-0.280). The latter was estimated by raising daily nest survival to the power of the length of the nesting period (30 days; Burns 2011). Predation was by far the greatest cause of nest failure. Including partial predation, it was responsible for $93 \%$ of failed nests. A small number of nests were abandoned (four), infertile (six eggs from five nests) or trampled (one). Models 1 and 2 (Table 2), the simplest models derived from the two full models, were similarly good at explaining our observed nest survival data $(\triangle \mathrm{AIC}=0.4)$. Model 1 contained site and laying date and model 2 index of cat

Table 1. Index of rat density at pasture sites - proportion of blocks or sticks chewed by rats per transect. GLMM with binomial errors, random effect of 1 |site/transect; $n=$ observations, 72 ; transects, 18 ; sites, 3 .

\begin{tabular}{llllc}
\hline Fixed effects & Estimate & S.E & z-value & $P$ \\
\hline Intercept (Broad Bottom) & -1.701 & 0.396 & -4.298 & $<0.001^{* * *}$ \\
Deadwood Plain & -1.123 & 0.575 & -1.950 & 0.051 \\
Man and Horse & -0.070 & 0.530 & -0.132 & 0.895 \\
Method - Wax Blocks & 0.471 & 0.228 & 2.070 & $0.039^{*}$ \\
\hline
\end{tabular}


Table 2. Survival of St Helena Plover nests at four study sites in relation to site, an index of cat density, laying date, nest age, year and the presence or absence of a nest camera.

\begin{tabular}{lllll}
\hline Model & $\Delta$ AICc & Likelihood & Parameters & Deviance \\
\hline 1. Site + laying date & 0 & 1 & 5 & 527.187 \\
2. Cat + laying date & 0.380 & 0.827 & 3 & 531.585 \\
3. Site + laying date + year & 1.077 & 0.584 & 6 & 526.252 \\
4. Cat + laying date + nest age & 1.721 & 0.423 & 4 & 530.918 \\
5. Site + laying date + nest age + year & 2.712 & 0.258 & 7 & 525.873 \\
6. Cat + laying date + nest age + year & 3.172 & 0.205 & 5 & 530.359 \\
7. Site + laying date + nest age + year + nest camera & 4.600 & 0.100 & 8 & 525.744 \\
8. Cat + laying date + nest age + year + nest camera & 5.066 & 0.0794 & 6 & 530.241 \\
\hline
\end{tabular}

density and laying date. Site is an uninformative factor, however, and variation in nest survival between sites does not in itself inform conservation management. Many aspects of the environment will differ between sites and it is therefore unexpected that a single aspect of the environment, the index of cat density, would predict nest survival equally well (Figure 3). There was a substantial reduction in nest survival with increasing laying date, from over $30 \%$ survival to hatching early in the breeding season to around $10 \%$ at the end. Burnham and Anderson (2002) suggest that models within two AIC units of the minimum may be worth considering. Models 3 and 4 fell within this margin, but the confidence intervals surrounding the additional terms (year - model 3 and nest age - model 4) spanned zero by a considerable margin, lending little support to these models.

From the sample of pairs closely monitored for a whole year it is clear that St Helena Plovers re-nest on multiple occasions after previous breeding failure (either nest or brood failure) or breeding success (at least one chick fledged) (Figure 4). The interval between nesting attempts tended to be shorter after breeding failure (median $=19.5$ days) than after success (median $=49.5$ days) (Kruskal-Wallis $X_{1}^{2}=3.643, P=0.056$ ). This difference in re-nesting interval did not, however, lead

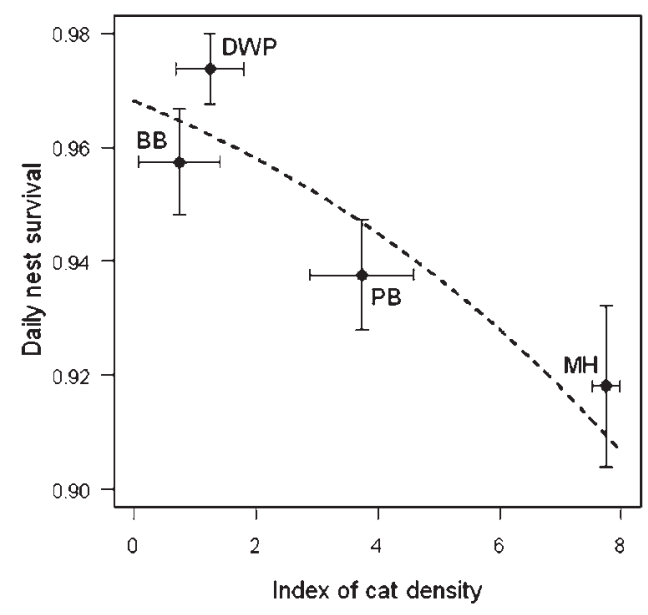

Figure 3. Survival of St Helena Plover nests and cat density. Dotted line: predicted relationship between nest survival and the index of cat density, inferred from a model using the index of cat density only. Points: observed relationship between nest survival, predicted from a model using site only, and the index of cat density ( $\overline{\mathrm{x}} \pm 1$ S.E) for each site. Key: BB - Broad Bottom, DWP - Deadwood Plain, MH - Man and Horse, PB - Prosperous Bay. 


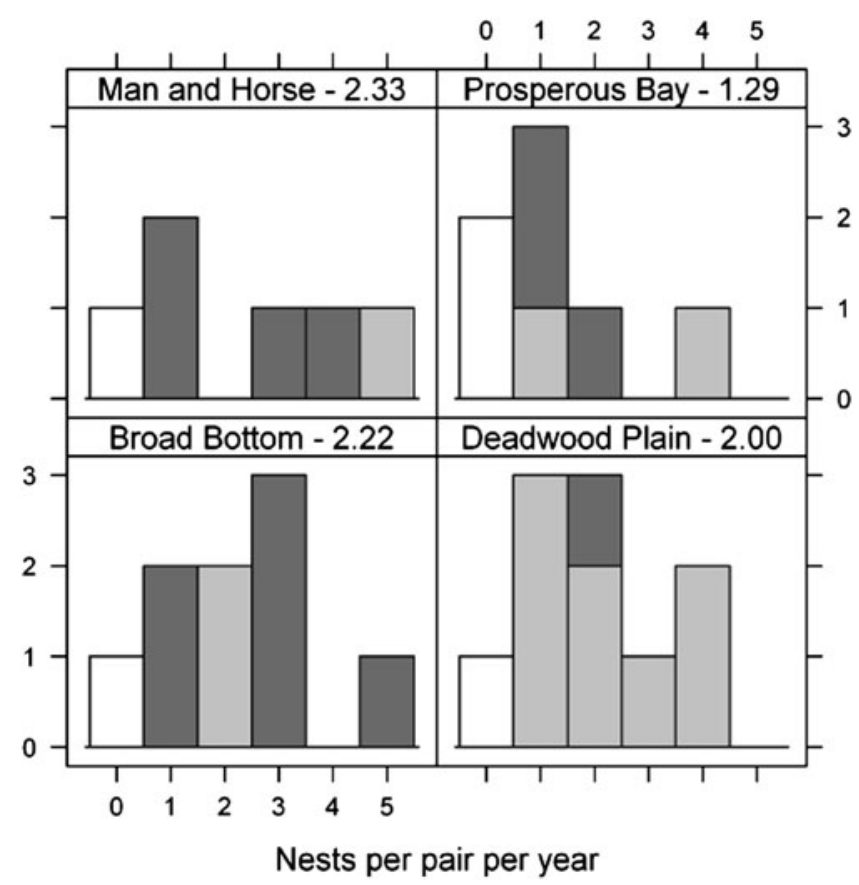

Figure 4. Frequency distribution of breeding attempts per year for breeding pairs of St Helena Plover. Key: dark grey - all breeding failures, light grey - at least one breeding success, white - no breeding attempts. The mean number of breeding attempts per pair at each site is shown next to the site name.

to different re-nesting intervals among study sites (Kruskal-Wallis, $X_{3}^{2}=2.605, P=0.457$ ), or differences among sites in the average number of breeding attempts pair ${ }^{-1}$ year ${ }^{-1}$ (KruskalWallis, $\bar{x}$ (grand) $=1.97, X_{3}^{2}=2.178, P=0.536$ ), or between pairs whose attempts all failed compared to those that had at least one success (median for both groups $=2$ ). Pairs at the site with the highest nest survival, Deadwood Plain, spent more days engaged in breeding activities (median $=89.5$ days per year) compared to those at other sites (median $=38.0$ days per year) (Kruskal-Wallis, $X_{1}^{2}=7.483, P=0.00623$ ).

\section{Discussion}

Our study had four key findings. Firstly, we found high rates of nest failure. Secondly, several introduced species were recorded as nest predators, of which cats were the most important. Thirdly, there was spatial variation in the densities of nest predators and variation in cat density was negatively correlated with nest survival. Fourthly, pairs at sites with low nesting survival did not respond by increasing the frequency or total number of nesting attempts per year.

\section{Nest predators}

All species recorded as nest predators of St Helena Plovers in this study have been introduced to the island since 1502 (Ashmole and Ashmole 2000). Whilst this is not unexpected, as there are now no native species that are likely to be egg eaters, it exemplifies the extent to which the fauna of oceanic islands can be altered after human colonisation. Certain species have often had 
devastating impacts when introduced outside of their native range; here all nest predators recorded are listed in the top 100 invasive species (Lowe et al. 2004). Of the species recorded, cats and rats are particularly notorious. They have been linked to numerous past extinctions and declines (Courchamp and Chapuis 2003) and are key threats to the fauna of the UK Overseas Territories (Hilton and Cuthbert 2010). The swamping of St Helena Plover nests by ants is uncommon, and was observed on only four occasions out of 173 nests monitored, including the one nest in the nest camera dataset. Nevertheless it is noteworthy, as although Pheodole megacephala has often been implicated in the decline of native ants and other invertebrates, evidence of direct impacts on vertebrates remains anecdotal (Wetterer 2007, Plentovich et al. 2009).

\section{Management options}

Given the level of nest predation by introduced species, one option for the conservation of the St Helena Plover would be to control or eradicate one or more of these introduced species. For instance, removing feral cats and strictly controlling domestic cats. Cats have been removed from islands of a similar size to St Helena, for example, its closest neighbour Ascension Island, but not from any with such a substantial human population (Oppel et al. 2011). Although the size of islands where successful rat eradication has been carried out has increased recent years, the largest of these, Campbell Island in New Zealand, is smaller than St Helena. This, coupled with the size of St Helena's human population, make it unlikely that rat eradication would be successful. The situation is made more complex because these two nest predator species, cats and rats, are themselves linked by predation. Any control of cats would risk an increase in rat populations through mesopredator release (Courchamp et al. 1999, Ritchie and Johnson 2009), thus reducing the predicted benefits to the St Helena Plover from fewer cats. An elevated rat population may also have negative impacts on other native species. There are over 400 endemic invertebrates and around 50 endemic plant species on St Helena, some of which are currently threatened by rats (Ashmole and Ashmole 2000, Bell and Floyd 2009).

\section{Impact of nest predators on nest survival and productivity}

The number of breeding attempts made by St Helena Plovers was similar across all study sites, regardless of nest survival. Multiple nesting attempts are considered an effective response to high nest predation, in particular in tropical latitudes where the breeding season is often extensive (Roper 2005, Lima 2009, Roper et al. 2010). Other aspects of the environment may limit the frequency of breeding attempts. Food availability has regularly been seen to limit the number of eggs a female bird can lay in a single season (Newton 1998) and may interact with predation risk. In areas with high numbers of predators, elevated food availability led to reduced nest predation (Zanette et al. 2006). A correlation between individual quality and nest survival could also explain the stability in breeding propensity observed in our study. For many island species, predators may have been introduced too recently for adaptation to high nest predation to occur. St Helena Plovers, however, are thought to descend from mainland African populations, where a wide range of predators would have been present and where similar species may nest up to II times in a year (Lloyd 2008). Additionally, it is thought that at least one of the endemic rail species on St Helena could have been an egg predator (Olson 1975).

Comparing the annual productivity of St Helena Plovers at our four study sites (range: $0.0425-0.213$ fledglings adult ${ }^{-1}$ year ${ }^{-1}$; additional information from Burns 2011) to the average annual adult mortality (0.171; Burns et al. 2013) indicate that some populations are producing insufficient fledglings to counterbalance adult mortality, even before mortality in the first year post-fledging is taken into consideration. This variation between populations in their ability to offset adult mortality through production is largely due to differences in nest survival. The strong correlation observed between nest survival and the index of cat density indicates that introduced predators are playing a part in limiting the population of St Helena Plovers locally. This comparison assumes constant brood survival between sites, but too few broods were followed 
to allow brood survival to be assessed at each site. Nevertheless, brood survival would have to exhibit a strong negative correlation to nest survival to alter our conclusions.

Our data provide further evidence of the negative impact of introduced species on oceanic islands and that certain species are particularly likely to become invasive when introduced to novel environments. Nevertheless, the persistence of the St Helena Plover alongside introduced predators appears possible, although nest predation by cats may become limiting locally. Reducing predator densities could be problematic since the nest predator community contains both apex (cat) and mesopredator (rat) species and therefore it is difficult to predict the ecosystem level implications of control. Understanding the implications of reducing the number of feral cats is a priority for future work. Investigating how other aspects on the environment influence productivity, for example food availability or vegetation structure, is equally important, as this could lead to a more sustainable and less controversial solution to low productivity.

\section{Acknowledgements}

Professor Xavier Espadaler kindly identified the ant species involved in nest predation from specimens. Several field assistants collected invaluable data for study: Annalea Beard, Robbie Watt and Chris Dodd. One author (FB) was supported by a University of Bath studentship with additional funding from the RSPB and Chester Zoo. We thank the St Helena National Trust, Eddie Duff, Phil Lambdon, the South Atlantic Invasive Species Project (an EU funded RSPB initiative), the Government of St Helena and all those in St Helena who have supported this project.

\section{References}

Ashmole, P. and Ashmole, M. (200o) St Helena and Ascension Island: a natural history. London: Anthony Nelson.

Bell, E. and Floyd, K. (2009) Rats on St Helena: Improving rodent control on St Helena Blenheim, NZ: Wildlife Management International Ltd. (Unpublished report).

BirdLife International (2009) Charadrius sanctaehelenae. IUCN Red List of Threatened Species <http://www.iucnredlist.org> (accessed 25 May 2010).

Bolton, M., Butcher, N., Sharpe, F., Stevens, D. and Fisher, G. (2007) Remote monitoring of nests using digital camera technology. J. Field Orn. 78: 213-220.

Burnham, K. P. and Anderson, D. R. (2002) Model selection and multimodel inference: a practical information theoretic approach. New York: Springer.

Burns, F. (2011) Conservation biology of the endangered St Helena Plover Charadrius sanctaehelenae. PhD thesis. Bath, UK: University of Bath.

Burns, F., Székely, T. and Bolton, M. (2010) Leg flags versus colour rings: a comparison of marking methods using a small shorebird, the St Helena Wirebird. Wader Study Group Bull. 117: 131-134.
Burns, F., McCulloch, N., Székely, T. and Bolton, M. (2013) No overall benefit of predator exclosure cages for the endangered St. Helena Plover Charadrius sanctaehelenae. Ibis 155: 397-401.

Courchamp, F. and Chapuis, J. M. P. (2003) Mammal invaders on islands: impact, control and control impact. Biol. Rev. 78: $347-383$.

Courchamp, F., Langlais, M. and Sugihara, G. (1999) Cats protecting birds: modelling the mesopredator release effect. J. Anim. Ecol. 68: 282-292.

Furness, R. W. and Furness, B. L. (1981) A technique for estimating the hatching dates of eggs of unknown laying date. Ibis 123: 98-102.

Gillespie, R. G. and Clague, D. A., eds. (2009) Encyclopedia of islands. Los Angeles: University of California Press.

Gillies, C. and Williams, D. (2002) Using tracking tunnels to monitor rodents and mustelids. Hamilton, NZ: Department of Conservation. (Unpublished report HAMRO-66179).

Harper, G. A. (2004) Feral cats on Stewart Island/Rakiura. Population regulation, home range size and habitat use. Wellington, NZ: Department of Conservation. 
Hilton, G. M. and Cuthbert, R. J. (2010) The catastrophic impact of invasive mammalian predators on birds of the UK Overseas Territories: a review and synthesis. Ibis 152 : 443-458.

Jones, E. and Coman, B. (1982) Ecology of the feral cat, Felis catus (L.), in south-eastern Australia III. ${ }^{*}$ Home ranges and population ecology in semiarid north-west Victoria. Austr. Wildl. Res. 9: 409-420.

Lima, S. L. (2009) Predators and the breeding bird: behavioral and reproductive flexibility under the risk of predation. Biol. Rev. 84: $485-513$.

Lloyd, P. (2008) Adult survival, dispersal and mate fidelity in the White-fronted Plover Charadrius marginatus. Ibis 150: 182-187.

Lowe, S., Browne, M., Boudjelas, S. and De Poorter, M. (2004) 100 of the world's worst invasive alien species: A selection from the Global Invasive Species Database. The Invasive Species Specialist Group (ISSG) a specialist group of the Species Survival Commission (SSC) of the World Conservation Union (IUCN).

McCulloch, N. M. (2009) Recent decline of the St Helena Wirebird Charadrius sanctaehelenae. Bird Conserv. Internatn. 19: 33-48.

McCulloch, N. M. and Norris, K. (2001) Diagnosing the cause of population changes: localized habitat change and the decline of the endangered St Helena Wirebird. J. Appl. Ecol. 38: 771-783.

Newton, I. (1998) Population limitation in birds. London: Academic Press.

Olson, S. L. (1975) The Paleornithology of St Helena Island, South Atlantic Ocean. Smithson. Contrib. Paleobiol. 23: 1-49.

Oppel, S., Beaven, B. M., Bolton, M., Vickery, J. and Bodey, T. W. (2011) Eradication of invasive mammals on islands inhabited by humans and domestic animals. Conserv. Biol. 25: 232-240.

Plentovich, S., Hebshi, A. and Conant, S. (2009) Detrimental effects of two widespread invasive ant species on weight and survival of colonial nesting seabirds in the Hawaiian Islands. Biol. Invasions 11: 289-298.

R Core Development and Team. (2004) R: A language and environment for statistical computing. Vienna, Austria: R Foundation for Statistical Computing.
Ricklefs, R. E. (1969) An analysis of nesting mortality in birds. Smithson. Contrib. Zool. 9: $1-48$.

Ritchie, E. G. and Johnson, C. N. (2009) Predator interactions, mesopredator release and biodiversity conservation. Ecol. Lett. 12: 982-998.

Roper, J. J. (2005) Try and try again: nest predation favors persistence in a Neotropical bird. Ornitol. Neotrop. 16: 253-262.

Roper, J. J., Sullivan, K. A. and Ricklefs, R. E. (2010) Avoid nest predation when predation rates are low, and other lessons: testing the tropical-temperate nest predation paradigm. Oikos 119: 719-729.

Rowlands, B. W., Trueman, T., Olson, S. L., McCulloch, M. N. and Brooke, R. K. (1998) The birds of St Helena. An annotated checklist. Tring, UK: British Ornithologists Union.

Thomas, M. D. (1999) Feasibility of using wax-blocks to measure rodent and possum abundance and changes in population size. Sci. for Conserv. 127C: 39-48.

van Aarde, R. J. (1979) Distribution and density of the feral house cat Felis catus on Marion Island. S. Afr. J. Antarct. Res. 9: 14-19.

van Aarde, R. J. and Skinner, J. D. (1981). The feral cat population at Marion Island: characteristics, colonization and control. Colloque sur les Ecosystemes Subantarctiques 51: 281-288. Paimpont, France: C.N.F.R.A.

Wetterer, J. K. (2007) Biology and impacts of Pacific Island invasive species. 3. The African big-headed ant, Pheidole megacephala (Hymenoptera: Formicidae). Pac. Sci. 61: 437-456.

Wetterer, J. K., Espadaler, X., Ashmole, N. P., Mendel, H., Cutler, C. and Endeman, J. (2007) Ants (Hymenoptera: Formicidae) of the South Atlantic islands of Ascension Island, St Helena, and Tristan da Cunha. Myrmecol. News 10: 29-37.

White, G. C. and Burnham, K. P. (1999) Program MARK: survival estimates from populations of marked animals. Bird Study 46: 120-139.

Zanette, L., Clinchy, M. and Smith, J. (2006) Combined food and predator effects on songbird nest survival and annual reproductive success: results from a bi-factorial experiment. Oecologia 147: 632-640. 
FIONA BURNS*, TAMÁS SZÉKELY

Biodiversity Lab, Department of Biology and Biochemistry, University of Bath, Bath, BA2 7AY, UK.

NEIL MCCULLOCH

Northern Ireland Environment Agency, Belfast, Northern Ireland.

\section{MARK BOLTON}

Conservation Science Department, Royal Society for the Protection of Birds, The Lodge, Sandy, SG19 2DL, UK.

*Author for correspondence; email:fiona.e.burns@bath.edu

Received 6 May 2012; revision accepted 5 February 2013 